\title{
Anekdoot kui niisugune
}

\section{$\underline{\text { Erkki Kõlu }}$}

Võõrsõnade leksikon defineerib anekdooti kui lühikest, huvitavat, enamasti väljamõeldud, kuid tabavat lookest mõnest lõbusast või naljakast juhtumist. Tegelikult ei ütle see definitsioon anekdoodi kohta peaaegu mitte midagi, lisaks on aga ka puudulik ja väär.

Anekdoot on üks nalja eriliike. Seejuures selline eriliik, mis on väga laialdaselt kasutatav. Tõenäoliselt pole olemas inimest, kes poleks mõnda anekdooti kuulnud, enamus on aga ka ise mõne anekdoodi rääkinud. Kui nali võib olla mingi kild, kellegi ütlus, mingi situatsiooni kirjeldus, mõne lõbusa või naljaka juhtumi ümberjutustus, siis anekdoot eeldab juba ülesehituses teatud tihendatust, välja on jäetud kõik ebaolulised detailid, ja muidugi lõpeb anekdoot puändiga. Ka pole anekdoodi kohta õige öelda, et ta on välja mõeldud, see väide on täiesti vale. Mis asi see anekdoot siis ikkagi on? Järgnevalt püüangi sellele vastata.

\section{ANEKDOOT KUI KOLLEKTIIVNE RAHVALOOMING}

Anekdootidel (absurdianekdoodid võibolla välja arvatud) puudub kindel autor. Anekdoodid tekivad tegelikest sündmustest edasirääkimise protsessis.

Iga anekdoodi algmaterjaliks on mingi tegelikult asetleidnud sündmus. Inimene, kes seda sündmust nägi või selle läbi elas, räägib sellest oma sõbrale, sugulasele või tuttavale. See jälle omakorda oma sõbrale, tuttavale, naabrile jne. Lugu edasi rääkides jätab inimene ühest küljest ära ebaolulisi detaile, mis jutustuse käiku pidurdavad ja lisainfot ei anna, teisest küljest lisab loole aga omapoolse nägemuse, liialdab ja moonutab, kuni esialgset sündmust, nö. anekdoodi allikat, pole enam võimalik tuvastada. Mida kauem anekdoot suust suhu liigub, seda rohkem ta muutub ja teiseneb.

Kas tekib hetk, mil võib väita, et mingi anekdoot on täiesti valmis? Sellist hetke ei teki, sest tänu pidevale edasirääkimisele muutuvad anekdoodid pidevalt. Muutuvad tegelased, sündmuskoht, olukord, detailid ja mõnikord isegi puänt. Nii võib ühel populaarsel anekdoodil olla hulgaliselt teisendeid. Näitena võib siin tuua anekdoodid Brezhnevist, mida nüüd Eestis Meri, Siimanni ja Savisaare kohta räägitakse. Niisiis on anekdoot pidevas muutumises ja liikumises, saavutamata kunagi lõplikku stabiilsust.

\section{MILLEL PÕHINEB ANEKDOOT}

Anekdoot põhineb kas situatsiooni-, karakteri- või sõnakoomikal. Sageli on anekdoodis ühte põimunud mitu koomika liiki, mõnikord isegi kõik kolm. Toon iga liigi kohta ühe näite. 


\section{SITUATSIOONIKOOMIKA}

Härra Müller tuleb koju ja viskub surijana tugitooli.

"Kallim, kutsu mulle kiiresti arst!" sosistab ta naisele. "On juhtunud midagi hirmsat: ma ei saa ennast enam sirgu ajada."

"Öelge, palun, kas on veel mingit lootust?" küsib kohkunud naine kohalejõudnud arstilt.

"On küll," vastab arst. "Talle mõjub väga hästi, kui ta oma ülemise püksinööbi vestinööbi keskmisest august lahti päästab."

Selles anekdoodis on tegemist ilmselge naljaka situatsiooniga, mille peale puänt üles ehitatud ongi.

\section{KARAKTERIKOOMIKA}

"Hei, John, olge hea ja tooge klaver siia!" hõikab lord oma teenrile.

"Kohe, sir!" vastab teener. "Kas hakkate mängima?"

"Ei, suitsetama. Ma unustasin tikud klaveri kaanele."

See anekdoot iseloomustab pisiseiga kaudu inglise lordi.

3. SÕNAKOOMIKA

Naine käsib mehel poodi minna. Mees ajab vastu:

"No kuhu ma lähen! Õues on niisugune ilm, et hea peremees ei aja sellisega koeragi välja."

"Taevake, eks sa mine siis ilma koerata," vastab naine.

Selles näites esineb sõnakoomika küllaltki tuntud väljendi "koerailm" kaudu.

\section{ANEKDOODILE ISELOOMULIKUD TUNNUSED}

\section{LÜHIDUS}

Anekdooti räägitakse edasi seni, kuni tema sisuks on ainult olulised detailid, st., kui iga järgmise detaili äravõtmine kahjustaks puänti või selleni viivat struktuuri. Kui anekdoot on pikk, lohisev, siis võib see tähendada, et:

a) tegemist on alles toormaterjaliga, mis pole veel nö. "lihvitud";

b) rääkija pole anekdoodist aru saanud või ei oska ta kuuldud anekdooti edasi anda. 


\section{TÄPSUS}

Lühivormina annab anekdoot edasi ainult seda, mida on tarvis puändini jõudmiseks, kahetähenduslikkusel ja ümberütlemisel pole anekdoodis kohta, kogu tee kuni lõpupuändini peab olema sirge ja selge.

\section{PUÄNT}

Anekdoodi üks kõige iseloomulikumaid tunnuseid on üllatav lõpplahendus, ilma selleta muutub anekdoot tavaliseks naljalooks või lõbusaks jutukeseks. Puänte on mitmesuguseid:

a) astmeline puänt, kus anekdoodil on mitu puänti, millest igaüks viib järgmise juurde ja kõik kokku viivad lõpp-puändini;

b) edasilükatud puänt, kus puänti tavaliselt korduste abil ikka ja jälle edasi lükatakse.

Edasilükkamise põhjuseks on põnevuse suurendamine ja tegelaste täpsema karakteriseerimise vajadus.

c) topeltpuänt, kus üks tegelastest ütleb välja asja, mis võib vabalt olla puänt, teine tegelane aga täiendab seda omapoolse puändiga.

\section{ANEKDOOT KUI REAALSUSE PEEGELPILT}

Ühest küljest on anekdoot see sisu, mille vormiks ta on. Teisest küljest näitab mingis kindlas ühiskonnas või mingi kindla rahvuse seast võrsunud anekdoot ühiskonna liikmete või rahvuse suhtumist mingisse teemasse või situatsiooni.

Ajalooliselt on välja kujunenud, et politseid ja sõjaväge kui jõustruktuure on anekdootides peaaegu alati negatiivselt kujutatud. Anekdoodid abielust peegeldavad vähemalt selles mõttes abikaasade võrdõiguslikkust, et neis jäävad nii mees kui ka naine lolli ossa võrdselt. Nõukogude Liidus sündinud poliitilised anekdoodid, mis alles mõni aeg tagasi massikommunikatsiooni vahendusel laiemalt tuntuks said, näitavad selgelt suhtumist nõukogude riiki, sotsialismi, kommunistlikku parteisse ja riigimeestesse.

Anekdoot käib ühiskondlikest sündmustest alati kuigipalju taga, sest olles inimestevahelise kommunikatsiooni tulemus, ei saa ta väga operatiivne olla. Justkui selle tõsiasja kompenseerimiseks elab anekdoot oma ajast palju kauem. Anekdoodi kangelane võib juba ammu surnud olla ja sündmus unustatud, kuid anekdoodis elavad nad edasi aastaid ja miks mitte ka sajandeid. Kokkuvõttes võib öelda, et anekdoot on reaalsuse peegelpilt, mis konkreetsel hetkel näitab meile juba möödunud reaalsust. Sellisena on anekdoot osa ühiskonna kultuurist ja ajaloost ning väärib seepärast säilitamist. 
Kuivõrd anekdoot on tegelikkuse peegeldus, siis on anekdootide temaatika sama rikkalik kui elu ise. Tõenäoliselt on kõige rohkem anekdoote abielust, sest see on juba tuhandeid aastaid olnud üks peamisi ja stabiilsemaid inimestevaheliste suhete vorme. Palju anekdoote on ka kohtupidamisest, sõjaväest, alkoholist jms. Enamasti ei kuulugi anekdoot puhtalt ühe teema alla, vaid mitme alla korraga.

Näiteks võib järgmise anekdoodi -

Kohtunik: "Kuidas te aru saite, et teie naine surnud on?"

Tunnistaja: "Kui ma koju tulin, siis virutasin talle jalaga, nagu ikka, aga tema isegi ei iitsatanud."

- liigitada kolme teemasse:

a) iseloomult kuulub ta musta huumori hulka;

b) tegelaste (mees räägib oma naisest) poolest kuulub ta abieluanekdootide sekka;

c) tegevuskoha poolest on tegemist kohtuanekdoodiga.

Eraldi teema moodustavad absurdianekdoodid, mis ainsa anekdootide liigina harilikult ei põhine tegelikult asetleidnud sündmustel.

Rahvuslikud anekdoodid iseloomustavad seda rahvust ja need võib jagada kaheks:

a) mingi kindla rahvuse hulgas kujunenud anekdoodid, mis seda rahvust iseloomustavad;

b) mingi kindla rahvuse hulgas kujunenud anekdoodid, mis iseloomustavad mõnda teist rahvust.

\section{ANEKDOODI ESITAJA}

Selle lühiülevaate lõpus peatu ma veel hetkeks anekdoodi esitajal. Kuivõrd anekdoodid levivad inimeselt inimesele peamiselt suulisel teel, on esitajal erakordselt tähtis roll. Anekdooti rääkides paneb esitaja oma miimika, zhestide ja intonatsiooniga anekdooti oma suhtumise, esitajapoolse emotsionaalsuse. Anekdoodi vastuvõtja ei võta vastu mitte ainult paljast teksti, vaid ka seda, kuidas talle anekdooti räägitakse. Kirjapanduna kaotab anekdoot esitaja eripära, jääb ainult see, mida saab edasi anda teksti abil. 